\title{
ESCRITOR Y PERIODISTA: LA DOBLE MILITANCIA DE VARGAS LLOSA
}

\author{
Héctor Soto
}

Si bien Mario Vargas Llosa dice que su primera vocación fue el teatro, y que ya antes de terminar la educación media intuía que lo suyo iba a ser la literatura, fue el periodismo el oficio que primero lo acogió. Es más - subraya Héctor Soto en este artículo-, el periodismo es también la actividad que Vargas Llosa ha desarrollado con mayor persistencia.

Descontado que hay muchos periodistas en sus ficciones y que a partir sobre todo de La guerra del fin del mundo muchas de sus novelas suponen un gran trabajo de reporteo y largas horas dedicadas a la investigación, no es posible sin embargo situar la producción periodística de Vargas Llosa en el mismo plano creativo que su producción literaria. Entre una y otra hay brechas insalvables. En sus crónicas, columnas y reportajes el autor apunta a la contingencia, desde el prisma de la reconstitución de los hechos, la racionalidad y la convicción. En sus novelas, en cambio, Vargas Llosa se topa con mundos irreductibles desde el punto intelectual, conectados al delirio, a las fuerzas del inconsciente y a los demonios que hay en cada ser humano. Tal vez este factor - advierte H. Soto- permita explicar el esplendor intelectual y narrativo de sus crónicas y la cuota de insensatez que anima casi siempre a sus héroes literarios.

HÉctor Soto. Abogado y periodista. Crítico de cine. Editor asociado de Cultura del diario La Tercera y profesor de la Facultad de Comunicación y Letras de la Universidad Diego Portales. Autor de Una vida crítica. 40 años de cinefilia (Alfaguara, 2008). Hector.soto@copesa.cl. 
A unque Vargas Llosa suele decir que su primera vocación fue el teatro, y que no la pudo desarrollar solo porque la escena teatral limeña de los años 50 era especialmente deprimente, lo más probable es que si el escritor hubiera fracasado en su carrera literaria el periodismo habría terminado siendo su gran refugio. Entre otras cosas, porque fue la actividad que primero lo cobijó y porque además nunca ha dejado de tener un pie puesto en los medios.

A diferencia de sus coqueterías con el teatro, acreditadas en unas cuantas piezas dramáticas y generadas básicamente en su fascinación por el verbo y las enormes posibilidades que ofrece su representación, la relación de Vargas Llosa con el periodismo acoge una masa crítica vibrante, variada y de grandes dimensiones. En este frente no solo hay más producción y una actividad más sostenida. También hay una resuelta voluntad suya de afrontar a fondo los dilemas éticos y expresivos del oficio. En otras palabras, la pasión y la intensidad con que Vargas Llosa ha problematizado el trabajo periodístico no tiene nada que ver con la reflexión relativamente escasa que le ha dedicado al teatro como actividad. Distancia y categoría: el teatro podrá cautivarlo y en los últimos años hasta le hizo ver que podía pasarlo bien trepándose a un escenario. Sin embargo, su nexo con el periodismo es más fuerte. El teatro podrá seducirlo, pero es el periodismo el que lo convoca, lo interpela, lo irrita, lo descompensa, lo complace, lo fascina, lo pone al día y lo mueve.

Así las cosas, es hasta lícito hablar en su caso de una doble militancia. Literatura y periodismo. Sobre este vértice, que los estudiantes de periodismo eligen como tema de tesis para hacer trabajos laboriosos y previsibles que nunca nadie leerá, Vargas Llosa acumuló y ha instalado una experiencia, un cuerpo creativo, una corriente de producción complementaria que no presentan muchas analogías en el gremio de los escritores ni en las distintas tribus de la literatura actual.

\section{1}

La más obvia conexión de Vargas Llosa con el periodismo insiste en que todavía no había cumplido los 16 años cuando entró a trabajar a un diario en Lima. Lo hizo por tres meses, entre el cuarto y el último 
año de la educación secundaria ${ }^{1}$. Llegó ahí sin muchas ilusiones, pero con un pálpito. A esa edad, tras dos años en el Colegio Militar Leoncio Prado, ya se le estaba haciendo cuesta arriba seguir respondiendo que iba ser marino cuando le preguntaban qué quería ser cuando grande. Ya no. El shock que le provocó la disciplina militar del colegio le había hecho ver que entre él y la vida uniformada las incompatibilidades eran totales y absolutas. Siendo así, el periodismo empezaba a aparecer casi por descarte en su horizonte. Por lo mismo, había comenzado a decir que luego del colegio estudiaría periodismo. Su papá se lo escuchó decir y, como tenía contacto con gente del oficio, puesto que por esa época manejaba una agencia de noticias, la International News Service, él mismo le gestionó con el director de un diario limeño una práctica durante el verano para que "viera desde adentro lo que era esa profesión"2.

Desde luego el tiempo que pasó en La Crónica tiene que haber sido una experiencia deslumbrante y definitiva para él. A esa edad, redactar noticias para el diario, cubrir inauguraciones y ceremonias, entrevistar a cantantes, empresarios de circo, sabios o toreros y andar de un lado a otro por Lima en una camioneta del diario, muchas veces con un fotógrafo al lado, debe haber sido mucho más que un bautizo. Qué duda cabe que en esos meses se templaron las ideas, las imágenes y la estética que Vargas Llosa asociaría para siempre en sus novelas al periodismo. En los años en que las salas de crónica y redacción hervían al compás del tecleo de las Underwood, cuando era imposible disociar el humo del cigarrillo de la inspiración del reportero, cuando el olor de la tinta y la pestilencia del plomo de las linotipias impregnaban las oficinas, las instalaciones y el edificio de los diarios, esa práctica tiene que haber sido un bombazo de aprendizaje moral. En cosa de días aprendió probablemente lo que un chico aprende en años. Vargas Llosa recuerda la escena con que se encontraba cuando volvía al periódico a escribir su nota, luego de haber reporteado durante la tarde. Tiene sentido volver a su descripción de ese momento por la cantidad de implícitos y verdades que encierra en unas cuantas líneas: "La llegada del jefe de la página policial, Becerrita, era el acontecimiento de cada noche. Si venía sobrio, cruzaba mudo y hosco la redacción hasta su escritorio, seguido por su adjunto, el pálido y rectilíneo Marcoz. Becerrita era bajito y fortachón, con los pelos engominados y una cara cuadrada y disgustada de perro

\footnotetext{
${ }^{1}$ Mario Vargas Llosa, El pez en el agua, 1993, p. 141.

${ }^{2}$ Ibídem, 1993, p. 121.
} 
bulldog, en la que destacaba, trazado a cordel, un bigotito linear, una hebra que parecía pintada con carboncillo. El había creado la página roja - la de grandes crímenes y hechos delictuosos-, uno de los mayores atractivos de La Crónica, y bastaba verlo y olerlo, con sus ojitos ácidos y granulados, en desvelo perpetuo, sus ternos replanchados y brillantes, hediondos a tabaco y sudor, de solapas llenas de lamparones y el nudo microscópico de su corbata grasienta, para adivinar que Becerrita era un ciudadano del infierno, que los submundos de la ciudad carecían de secretos para él"3.

Para un chico que dos años antes había sido arrastrado al Colegio Militar Leoncio Prado, porque su papá estaba convencido de que la rudeza y disciplina de ese plantel acabaría con el engreimiento y la fragilidad del niño, esa experiencia tiene que haber sido muy traumática. El padre consideraba que la madre, los abuelos y los tíos de Cochabamba lo habían consentido más de la cuenta en sus años de ausencia. Dentro de sus planes, el Leoncio Prado estaba llamado a endurecerlo y convertirlo en un hombre. Cuando Vargas Llosa entró a ese colegio ni la literatura ni el teatro ni menos el periodismo figuraban en el radar de sus intereses vocacionales. Sin embargo, fue ahí donde su futuro se comenzó a aclarar y se aclararía por donde su padre menos lo imaginó. El chico desarrolló una odiosidad con el padre que lo induciría a contrariarlo en todo. Y, paralelamente, comenzaría a descubrir sus habilidades y gustos en la esfera de intereses que su padre despreciaba. Al margen de las tensiones con sus mayores, no es un misterio para nadie que la identidad comienza a formarse el día en que los jóvenes descubren qué les interesa de la vida y para qué pueden llegar a ser buenos.

Como era previsible en su caso que ocurriera, el colegio fue una experiencia muy dramática. En los tres años del Leoncio Prado "descubrí — dice Vargas Llosa - la crueldad, el miedo, el rencor, dimensión tortuosa y violenta que está siempre, a veces más y a veces menos, contrapesando el lado generoso y bienhechor de todo destino humano". Descubrió también otra cosa, por oposición, como él mismo lo reconoce: "Y es probable que sin el desprecio de mi progenitor por la literatura, nunca hubiera perseverado yo de manera tan obstinada en lo que era entonces un juego, pero se iría convirtiendo en algo obsesivo y perentorio: una vocación. Si en esos años no hubiera sufrido tanto a su

\footnotetext{
${ }^{3}$ Mario Vargas Llosa, El pez en el agua, 1993, p. 142.
} 
lado, y no hubiera sentido que aquello era lo que más podía decepcionarlo, probablemente no sería ahora un escritor"4.

Las razones que tuvo el papá para ponerlo ahí son de una ramplonería atronadora pero que no debiera sorprendernos: "Su idea era la de muchos papás de clase media con hijos díscolos, rebeldes, inhibidos o sospechosos de mariconería: que un colegio militar, con instructores que eran oficiales de carrera, haría de ellos hombrecitos disciplinados, corajudos, respetuosos de la autoridad y con los huevos bien puestos"5.

Cuesta creer que ese internado brutal - donde el bautizo de recepción eran feroces patadas en el trasero, humillaciones denigrantes en público y masturbaciones forzadas frente a los más grandes, entre otras delicadezas - lejos de secar para siempre una vocación literaria que por lo demás aún no se había manifestado plenamente cuando ingresó, haya sido templada a golpes precisamente en esos lodos, al punto de volverse con el tiempo una opción personal intransable.

Sí, sería la literatura, no la marina, lo suyo. Y también a su modo lo sería el periodismo, al menos en la parte no contaminada por la ética y la estética del fracaso de los periodistas que él había conocido y que pertenecían a un mundo que lo contrariaba profundamente. ¿Cuánto incidían en esa percepción las sombras que debió haber proyectado sobre la profesión la agencia informativa del padre? Es difícil saberlo. Su padre terminaría siendo con el tiempo un gran looser. Su proyecto de encontrar mejores horizontes en los Estados Unidos —adonde habían emigrado dos hijos suyos engendrados fuera del matrimonio- fracasó y tanto él como su mamá acabarían trabajando como obreros en Los Ángeles. Durante trece años, la mamá fue tejedora en una manufacturera de telas y él se desempeñó por un lapso parecido en una fábrica de zapatos. Después los dos oficiarían de porteros en una sinagoga en Los Ángeles ${ }^{6}$. En cualquier caso, si de niño existió en su cabeza algún nexo entre el periodismo y su padre, es obvio que esta actividad le debe haber parecido muy poco glamorosa. Lo salvó el hecho de que este oficio tiene también otros frentes, partes más sanas, por así decirlo, que no se tocan con las miserias del gremio. Es el caso, por ejemplo, del periodismo de crónica, de columnas y de reportajes, que son precisamente los géneros que Vargas Llosa ha cultivado de manera más persistente. Con

\footnotetext{
${ }^{4}$ Mario Vargas Llosa, El pez en el agua, 1993, p. 101.

${ }^{5}$ Ibídem, 1993, p. 101.

${ }^{6}$ Ibídem, 1993, p. 339.
} 
una salvedad, eso sí: lo ha cultivado de manera independiente, al margen de las salas de redacción, desde afuera, poniendo él las reglas del juego y ejerciendo el oficio con entera libertad.

Si bien en distintos pasajes de la vida de Vargas Llosa la doble militancia en la literatura y el periodismo podría ser explicada en los inicios a la luz de consideraciones estrictamente económicas, porque al fin y al cabo de algo hay que vivir, es evidente que a esas alturas la conexión del Premio Nobel con la prensa es mucho más profunda.

Es verdad que para el escritor las entrevistas, la crónicas y las columnas fueron en varios momentos de su vida auténticas tablas de supervivencia. Los diarios no pagan demasiado, pero eso puede ser una fortuna cuando el escritor recién está partiendo o - peor aún- cuando a pesar de haber debutado sigue siendo un perfecto desconocido. Varias veces él mismo ha contado que luego de casarse con la tía Julia llegó a acumular hasta seis o siete empleos simultáneos para poder sufragar los gastos básicos de la pareja. En realidad, eran pobres como las ratas. De ese total, tres o cuatro tenían que ver con el periodismo.

También es cierto que rara vez los escritores pueden vivir únicamente de la literatura, entendiendo por tal los ingresos generados vía derechos de autor. Eso es difícil incluso en el caso de autores célebres. Por eso los escritores dan clases, se emplean en universidades, ofrecen talleres y escriben en los diarios. Para muchos, no son irrelevantes los ingresos habituales estables que la prensa les pueda garantizar.

Sin embargo, algo dice que si a Vargas Llosa los diarios no le pagaran por sus artículos, bueno, sería entonces él quien pagaría por publicarlos. Dicho así, es obvio que se trata de una exageración. Pero el chascarro tiene un punto de verdad en cuanto que la presencia en los medios, el estar en las líneas de fuego del debate público y de la actualidad, el opinar e influir, es para Vargas Llosa un aspecto importante - muy importante - en el camino que escogió vocacionalmente y en su propia concepción de la literatura.

Vargas Llosa no se hizo precisamente escritor porque estuviera devorado por la pasión incontenible del arte por el arte. No se hizo escritor por amor únicamente a la literatura. No se hizo escritor porque 
tuviera muchas historias "literarias" o de escritores que contar. Nada de eso. Sartreano convencido, no obstante haber sido un joven de corazón dividido entre Sartre y Camus en los años 50, Vargas Llosa se hizo escritor porque quería comprometerse con su época y porque sentía que desde la literatura, desde la escritura, podía en alguna pequeña o gran escala contribuir a un mundo mejor. En lo más profundo, su modelo fue el de la literatura comprometida y en esto, aun hoy, cuando su signo ideológico actual podría ser muy distinto al de entonces, las cosas no han cambiado mucho. El suyo, claro, no es el modelo del realismo socialista. Nunca lo fue. Tampoco el de la literatura instrumental al servicio de objetivos políticos o ideológicos o de valores extraliterarios. Pero sí es el modelo del escritor que es capaz de ensuciarse las manos con la Historia y de tomar partido en la sociedad. El del escritor que no necesariamente se tapa la nariz cuando se enfrenta, negocia o se expone a las lógicas del poder. El artista sartreano no es puro y no está cerrado de antemano a entender las miserias y submundos de la política. Qué diablos, así es el mundo, se dirá, y tendrá que aceptarlo y entenderlo. Entenderlo, eso sí, para tratar de cambiarlo.

Hay que comprender el momento en que Vargas Llosa comienza a escribir. Para eso, no solo hay que fijarse en el deprimente clima intelectual peruano de fines de la dictadura de Odría en los años 50 sino también en los bullentes estímulos de la compresora cultural francesa de esa época, cuando el existencialismo se cruzaba con la pintura cubista, cuando la épica de la rebeldía de Albert Camus ajustaba cuentas con el magisterio populista de Sartre halagando a los jóvenes o cuando la voz desdeñosa de Juliette Greco le ponía música a los primeros atisbos del nouveau roman. Es posible que para la conciencia elitista francesa de esa época el mundo empezara en Le Monde y terminara en Le Figaro. Probablemente era un mundo mucho más chico de lo que entonces parecía. Pero los destellos de la Ciudad Luz parecían iluminar sobre medio mundo. Eran los momentos en que estaba abandonando la escena André Gide, debutando Robbe Grillet y llegando a reclamar lo suyo los cineastas de la nouvelle vague. París sí que era realmente una fiesta. Fue la época en que la inteligencia se convertiría, como dijo alguna vez un cineasta brasileño, en una perversión estrictamente francesa.

Cuando Vargas Llosa llega a París por primera vez en 1960, la verdad es que ya llevaba mucho tiempo conectado a la distancia a esos furores. Hay que leer las crónicas que dedicó al tema —están conteni- 
das en el primer tomo de Contra viento y marea $^{7}$ - para dimensionar el impacto que le generaron. Son apasionantes esas crónicas. Y lo son no sólo porque desde siempre Vargas Llosa fue un cronista de prosa espléndida y capaz de procesar en sus escritos una enorme cantidad de información sino también porque, leídas de corrido, una tras otra, dan cuenta de una evolución intelectual perceptible, muy jugada y dolorosa. Qué duda cabe: la procesión debe haber ido por dentro. El Vargas Llosa que llega a vivir a París el año 60 con Julia Urquidi es mucho, muchísimo, más incondicional de Sartre que el que regresa al Perú cinco años después. Por lo demás, es un período en el que corre mucha agua bajo los puentes. Sartre ya había declarado que el marxismo era "la filosofía insuperable de nuestro tiempo" y explicitado su alineamiento con la Unión Soviética. Las divisiones al interior de la tribu intelectual francesa se estaban haciendo cada vez más profundas. En la vida privada del escritor las cosas también se estaban saliendo de control: divorcio en 1964; nuevo matrimonio, ahora con Patricia Llosa, su prima, un año después y de nuevo vuelta a París, esta vez con intenciones mucho más serias de radicarse allá. Le fallan todas las becas y ayudas con que contaba para facilitar su aterrizaje y poder contar en los primeros meses con algún margen de tranquilidad. Nada le resultó. Pero igual se fue, a lo que viniera. Preferible saltar al vacío que quedarse. Si en algo no le

${ }^{7}$ Mario Vargas Llosa, Contra viento y marea (1962-1982) [1983], Sudamericana-Planeta, 1985. Es un libro extraordinario. Seix Barral publicó un segundo y un tercer tomo en 1986 y 1990 respectivamente. La introducción contiene una verdadera declaración de principios del autor: "Al final de tan abundante volumen, el abnegado lector descubrirá con la misma perplejidad que yo - escribe Vargas Llosa- que el libro contiene más dudas que certidumbres y que éstas son tan simples y breves que caben en cuatro palabras: que la literatura, a fin de cuentas, importa más que la política, a la que todo escritor debería cerrarle el paso, recordarle su lugar y contrarrestar sus estropicios; que la libertad es inseparable de la justicia social y que quienes las disocian, para sacrificar la primera con el argumento de alcanzar más pronto la segunda, son los verdaderos bárbaros de nuestro tiempo; que, por oportunismo, cobardía o ceguera, el intelectual contemporáneo suele ser un diligente aliado de la barbarie; y, por último, que aunque el pesimismo parezca ser una actitud más realista que el optimismo para encarar el futuro inmediato de América Latina, esto de ninguna manera significa resignarse y alzar los brazos, sino seguir batallando, en esos dos frentes, que, en verdad, son uno solo: contra el horror de la dictadura militar, la explotación económica, el hambre, la tortura, la ignorancia, y contra el horror de la dictadura ideológica, los partidos únicos, el terrorismo, la censura, el dogma y los crímenes justificados con la coartada de la historia". 
cabía duda era en que tenía que irse del Perú — sí o sí- para cumplir su destino. Vaya uno a saber en qué hubiera terminado de no haber podido hacerlo. Posiblemente no en la literatura. Con suerte, quizás, en el periodismo. Para todos los efectos prácticos, habría sido un hombre al agua.

En la biografía de Vargas Llosa el periodismo explica una parte no menor de sus actividades. Es una pasión y también un arma. Es un tema recurrente en sus novelas. Es un complemento del trabajo literario. Y es también una modalidad de trabajo que le ha sido de enorme utilidad para el desarrollo y la escritura de varias de sus novelas. A partir de La guerra del fin del mundo, pero sobre todo en los últimos años, Vargas Llosa ha devenido en un novelista que dedica gran esfuerzo a reportear sus historias. Se diría que allí el periodista se confunde con el escritor. Hay mucha investigación en títulos como La fiesta del Chivo, El Paraíso en la otra esquina y - ni qué decirlo- en El sueño del cel$t a$, donde la cantidad de datos y el flujo de información que el escritor pesquisó sobre la vida del cónsul británico Roger Casement en el Congo belga, en la Amazonía peruana y en Irlanda puede llegar a ser agotador.

Vargas Llosa necesita el periodismo. Lo necesita porque sabiendo que el escritor puede llegar a influir en el muy largo plazo, él también quiere influir en lo inmediato. No quiere sustraerse a nada. Quiere estar lejos y quiere estar cerca. Quiere estar en todas. Fue Sartre quien le enseñó que las palabras — cualquiera sea su soporte - son un arma que debe usarse para defender las mejores opciones ${ }^{8}$. Y no hay oportunidades que perder. Vargas Llosa quiere entenderse con las lentas circunvalaciones de la historia y también quiere ser parte del debate público de esta época. Tiene la sensación de que en lo grande y en lo chico, en el tráfago del día a día y en la pesada legalidad de los ciclos históricos, se están librando batallas decisivas para la cultura y el humanismo, para la decencia y la libertad.

Todo esto, que a cualquier escritor sajón le parecería tremendamente sospechoso, entre otras cosas porque ellos ven, si se quiere, el espacio de la literatura en el extremo opuesto de los vértices de la política

${ }^{8}$ Mario Vargas Llosa, El lenguaje de la pasión, 2000, p. 10. 
y la actualidad, y en ningún caso como un continuo que comienza - por así decirlo- en el municipio y termina en el infinito, es al final la gran apuesta de Vargas Llosa. Eso se ve en lo que hace y en lo que escribe. También se nota en el tipo de novela que cultiva, esa, la novela-río cuya matriz terminó definiendo Balzac, capaz de cubrir toda una época, de capturar el espíritu de los tiempos, de reivindicar una gran galería de personajes y de hacer entrar a las páginas de un libro un mundo cuya fisonomía y cuyos deslindes coinciden con increíble exactitud con los del mundo que está allá afuera.

Maestro en el arte de la crónica, Vargas Llosa comenzó a escribir la serie Piedra de Toque en julio de 1977. En realidad él venía publicando de mucho tiempo antes. Vargas Llosa fue una de las tantas plumas que la Agencia Efe reclutó para un servicio de artículos semanales que alternaba los nombres de Octavio Paz, José Donoso, Carlos Fuentes, Juan Carlos Onetti, entre muchos otros. Pero ese año Piedra de Toque pasa a ser la marca registrada de Vargas Llosa. Quiso bautizar su espacio con el nombre de esa piedra oscura y un tanto legendaria que sirve para conocer la autenticidad de las alhajas y metales. Las suyas son dos columnas al mes en las cuales repasa la actualidad informativa, concediéndose pocas licencias para temas literarios. A lo más escribe acerca de escritores con motivo de aniversarios, muertes o acontecimientos muy significativos del mundo editorial. La idea es que estas crónicas y columnas amplíen su mundo, no que lo constriñan. Básicamente entonces el eje de estos artículos está en la política, en la cultura entendida en su sentido más amplio, en los derechos ciudadanos, en los cambios sociales y en el escenario internacional. A veces, muy rara vez, se le filtran en sus columnas aspectos biográficos, como cuando escribió este año sobre la casa de su familia en Arequipa ${ }^{9}$. Pero no tienen nada de diario de vida y mucho menos podrían ser vistas como un puente para encaminar nuevos lectores hacia su literatura. Se diría que el sentido de las columnas es más bien el inverso: el propósito sería traer de vuelta al escritor del mundo de la ficción al mundo real.

${ }^{9}$ Mario Vargas Llosa, "La casa de Arequipa", La Tercera, 27 de marzo 
Treinta y cuatro años después de publicada la primera, las columnas de Piedra de Toque en la práctica ya configuran un género aparte. Lleva ya muchos años publicándolas en el diario El País y en una larga cadena de diarios sindicados. En Chile las publicó en otro tiempo el vespertino La Segunda hasta que algunos desencuentros, retrasos y saltos en la periodicidad de las columnas en la época que comentó el apresamiento del general Pinochet en Londres dañaron la relación entre el columnista y el diario. A partir de ese momento la crónica pasó a las páginas del cuerpo de Reportajes de La Tercera.

Las crónicas de Vargas Llosa son ricas en aliento narrativo e inconfundibles en la mirada que tienen sobre sus temas. Sin embargo, no siempre se caracterizan por desplegar un fuerte discurso opinativo o crítico. Sus textos periodísticos no son el reino de la pura opinión. La llamada "opinología" no es su especialidad. Vargas Llosa sobre todo cuenta, describe, sitúa o rescata un personaje o una situación. Las suyas, antes que nada, son las crónicas de un escritor insuperable a la hora de narrar y de contarle al lector una historia. En ese plano desde luego Vargas Llosa es un monstruo. Un monstruo capaz de convertir hasta el más árido debate de ideas en un cuento, en un relato, en una historia. Esta habilidad es el punto fuerte de sus artículos. Los suyos siempre entregan información y cuentan una historia cruzada por experiencias personales. En esto, y no solo en esto, se apartan del esquema de la columna de opinión, en el cual alguien se siente convocado a expresar desde su metro cuadrado sus puntos de vista, sus juicios, sobre lo que le parece y lo que no le parece. Este género, que está relacionado más con la opinología que con el columnismo, está entre los más lamentables subproductos del periodismo del yo y en estricto rigor no tiene nada que ver con lo que hace Mario Vargas Llosa. Cuando no hay información, cuando la columna no abre mundos sino que más bien los cierra, cuando el énfasis está puesto no en lo que sucede ni en lo que ocurrió sino en el juicio del opinólogo, el yo creo que..., el yo pienso que..., el a mí me parece $q u e . .$. termina teniendo un interés muy limitado. En el mejor de los casos, el interés será equivalente al de quien emita los juicios. Poco, la mayoría de las veces. En general este tipo de ejercicios funciona mejor en la televisión que en la prensa; y, puesto que estamos en esas, mejor en los realities que en los programa de conversación.

Lo que hace Vargas Llosa responde a algo enteramente diferente. Estas son las crónicas y las columnas de un escritor devorado por la 
erótica del relato, que siempre tiene mucho más cuento que transmitir que opiniones que desplegar. Estas son evidencias de la curiosidad intelectual de un autor que no está conforme con lo que sabe y que siempre está interesado en saber más, en conocer mejor, en recoger mejores antecedentes y en superar la estrechez de su mundo.

Hay probablemente pocos escritores movidos por semejantes niveles de curiosidad y apertura mental. A Vargas Llosa le interesa de verdad el mundo y tanto le fascina que nunca ha tenido que recalar en sus novelas en el argumento típico del novelista sin mucho mundo, enjaulado en su pieza o biblioteca, y que suele escribir de lo único que sabe y conoce: de escritores que a su vez están escribiendo una novela. No, por favor: Vargas Llosa prefiere otros temas y de hecho, luego de haber escrito algunas novelas monumentales de indudable carga autobiográfica, ha publicado páginas memorables sobre las dictaduras latinoamericanas (La fiesta del Chivo), el feminismo de comienzos del siglo pasado ( $E l$ Paraíso en la otra esquina), el amor no correspondido (Travesuras de la niña mala), las guerras dictadas por el fanatismo político (La guerra del fin del mundo), el terrorismo latinoamericano (Historia de Mayta) o el colonialismo europeo (El sueño del celta).

No sería raro que fuera esta voracidad por saber, por descubrir, por conocer, unida a la disciplina del relato y a la experiencia personal, el factor que garantiza renovada vigencia a las crónicas o columnas de Vargas Llosa. Es impresionante lo bien que se mantienen incluso las publicadas hace casi medio siglo. No se caen de las manos: sorprenden, interpelan y provocan como si hubieran sido escritas la semana pasada. Mientras nombres preclaros del columnismo latinoamericano y mundial se volvieron farragosos y anacrónicos, los escritos de Vargas Llosa conservan intacta la pólvora, la efectividad narrativa y la tensión intelectual que siempre los distinguió.

\section{5}

Si los años 60 fueron para Vargas Llosa la etapa en que su proyecto literario irrumpió con una fuerza insospechada en el panorama de las letras latinoamericanas - logrando un reconocimiento que difícilmente podría haber estado en sus cálculos-, la década siguiente corresponde al período de enorme conmoción política e intelectual. Va a ser en esos años cuando el escritor se separará de la manada. Va a ser 
en los 70 cuando rompa con el partido mayoritario de la intelectualidad latinoamericana, el partido de la revolución cubana. Perderá amigos y ganará enemistades, descalificaciones y críticas. Por esa década sus novelas se tornan menos ortodoxas respecto de la matriz sartreana y en las dos que publica la ambición social es significativamente menor. Pantaleón y las visitadoras (1973) y La tía Julia y el escribidor (1977) son obras mucho más lúdicas. Una y otra están libres de la pretensión de componer un gran fresco social. Las dos son obras que en cierto modo muestran a un sujeto que ya comienza a venir de vuelta. Las dos abren la puerta al humor (que para Sartre fue siempre un terreno vedado) y, en esa medida, hablan de un escritor que se está volviendo cada vez más libre en sus temas, cada vez más autónomo en las formas y cada vez más personal en sus maneras de aproximarse a la realidad.

No es que en los años 70 Vargas Llosa cambiara radicalmente su manera de pensar. Lo que sí cambia es el lugar desde donde quería seguir pensando.

El proceso fue rápido pero no fulminante. Con Cuba el corte sobrevino a raíz del caso Padilla. El episodio parte una noche de abril en 1971, cuando en una sala de la sede de la Unión de Escritores Cubanos, ante la flor y nata de la escena literaria cubana, el poeta Heberto Padilla, que había trabajado un tiempo en la embajada cubana en Londres, lee ante sus colegas una siniestra autoinculpación de deslealtad a la revolución. Era su "confesión". Lo mismo hacen otros poetas díscolos. En sus declaraciones las víctimas inculpan y comprometen a colaboradores y amigos en supuestas conductas antirrevolucionarias y opiniones desviacionistas. Padilla, que con su esposa ya llevaba 38 días detenido y había soportado a lo menos dos años de hostilidades del régimen, en el mismo acto abjura de su libro Fuera del juego, escrito cuatro años antes y que un jurado encabezado por el viejo Lezama Lima había galardonado, y declara haber sido un "escritor burgués, indigno de ser leído por los obreros e incapaz de entender la complejidad del proceso revolucionario".

Esa sería la piedra que dividiría las aguas en el apoyo hasta ese momento monolítico e incondicional de la intelectualidad latinoamericana y mundial a la revolución cubana. Puesto que en la forma, en el libreto, en la escenografía y en el trasfondo político todo coincidía con la moral y la ritualidad de los Procesos de Moscú estrenados por Stalin en 1938, la reacción no se hizo esperar. El 5 de abril Vargas Llosa dirigió una carta a Haydée Santa María, directora de la revista Casa de las 
Américas, renunciando al comité de la publicación ${ }^{10}$. Días después aparece en Le Monde la carta pública a Fidel Castro redactada por Vargas Llosa y suscrita por un amplio grupo de figuras del mundo artístico e intelectual (Jean Paul Sartre, Simone de Beauvoir, Susan Sontag, Carlos Fuentes, Michel Leiris, Juan Marsé, P. P. Pasolini, Juan Rulfo, Alain Resnais, Jorge Semprún, entre muchos otros). Carlos Barral, Cortázar y García Márquez también condenaron la acción, pero después retiraron el nombre. El texto de la nota es muy enérgico desde la primera línea. "Creemos nuestro deber comunicarle nuestra vergüenza y nuestra cólera". Nadie nunca le había hablado a Fidel Castro así: "Con la misma vehemencia que hemos defendido desde el primer día la revolución cubana, que nos parecía ejemplar en su respeto al ser humano y en su lucha por su liberación, lo exhortamos a evitar a Cuba el oscurantismo dogmático, la xenofobia cultural y el sistema represivo que impuso el estalinismo en los países socialistas, y del que fueron manifestaciones flagrantes sucesos similares a los que están ocurriendo en Cuba"11.

La reacción del gobierno cubano y de su líder no se hizo esperar. Castro los acusa de ser unos "canallas". Lanza una condena implacable sobre los escritores latinoamericanos que viven en Europa. Y les advierte de la prohibición de entrar a Cuba por tiempo indefinido.

Aunque después del incidente los puentes de comunicación con La Habana parecían definitivamente cortados, poco más de un mes después, el 28 de mayo, Vargas Llosa entregó a la prensa una declaración en la cual todavía seguía reivindicando como propia la causa de la revolución: "Cierta prensa está usando mi renuncia al comité de la revista Casa de las Américas para atacar a la revolución cubana desde una perspectiva imperialista y reaccionaria. Quiero salir al frente de esa sucia maniobra y desautorizar enérgicamente el uso de mi nombre en una campaña contra el socialismo cubano y la revolución latinoamericana. Mi renuncia es un acto de protesta contra un hecho específico, que sigo considerando lamentable, pero no es ni puede ser un acto hostil contra la revolución cubana, cuyas realizaciones formidables para el pueblo de Cuba son llevadas a cabo en condiciones verdaderamente heroicas que he podido verificar personalmente en repetidos viajes a la isla. El derecho a la crítica y a la discrepancia — sueña en ese momento Vargas Llo-

${ }^{10}$ Mario Vargas Llosa, “Carta a Haydée Santa María”, 1985, p. 164.

${ }^{11}$ Mario Vargas Llosa, “Carta de Fidel Castro”, 1985, p. 166. 
sa - no es un privilegio burgués. Al contrario, sólo el socialismo puede sentar las bases de una verdadera justicia social, dar a expresiones como libertad de opinión, libertad de creación su verdadero sentido. Es en uso de ese derecho socialista y revolucionario que he discrepado del discurso de Fidel sobre el problema cultural, que he criticado lo ocurrido con Heberto Padilla y otros escritores. Lo hice cuando los acontecimientos de Checoslovaquia y lo seguiré haciendo cada vez que lo crea legítimo, porque ésa es mi obligación como escritor. Pero que nadie se engañe: con todos sus errores, la revolución cubana es, hoy mismo, una sociedad más justa que cualquier otra sociedad latinoamericana y defenderla es para mí un deber apremiante y honroso"12.

¿Cómo es que pensando así, incluso después del portazo insultante de Fidel Castro, va a llegar un momento en que Vargas Llosa cruzará el Rubicón, para instalarse ya a fines de los años 70 en el núcleo duro del pensamiento liberal?

Tienen que haber sido muchas las tensiones, deslealtades, vacíos y exclusiones que se fueron acumulando en su contra. Algo debe haber incidido, por ejemplo, su polémica con Ángel Rama, a quien Vargas Llosa acusó de apelar a las armas del terrorismo histórico, de la excomunión ideológica y del chantaje político. Ángel Rama había destrozado el ensayo de Vargas Llosa sobre la obra de García Márquez, Historia de un deicidio ${ }^{13}$, y lo hizo con la fraseología político-literaria entonces en boga. No hay mucho de que extrañarse: estos exabruptos, estas coartadas, eran moneda corriente en el debate intelectual de esos años.

Luego viene su distanciamiento de Gabriel García Márquez, que hasta entonces había sido su gran amigo. Hacia 1976 era sin embargo notoria la brecha entre las opciones políticas de ambos. Pero se da por hecho que no es la política lo que los enemistó ese año en México, cuando Vargas Llosa le puso un puño en plena cara al autor de Cien años de soledad. La versión más difundida dice que alguien se propasó. Habían sido grandes compinches y la enemistad duró treinta años, hasta que ambos se reconciliaron el año 2007.

Después sobrevino el escándalo por la publicación de Persona non grata, de Jorge Edwards, que sacó a su autor, diplomático y nove-

${ }^{12}$ Mario Vargas Llosa, "Entrevista exclusiva a V. L1.”, 1985, p. 171.

${ }^{13}$ Mario Vargas Llosa, García Márquez, Historia de un deicidio, 1971. Se trata de un libro muy difícil de encontrar. Nunca se volvió a reeditar, pero ha sido incluido recientemente en las Obras completas del autor. 
lista, del círculo de protección de la izquierda castrista expulsándolo a las tinieblas del error. Vargas Llosa no solo le tenderá una mano sino que escribirá una encarnizada defensa del libro.

A eso siguió su redescubrimiento de Camus, paralelo al desvanecimiento de Sartre en sus jerarquizaciones intelectuales. A Camus lo había leído desde muy temprano, pero con sesgo, precisamente porque Sartre lo había subestimado. Vargas Llosa rescata sobre todo de Camus su testimonio: "Vivió convencido de que la política era sólo una provincia de la experiencia humana, que ésta era más ancha y compleja que aquélla, y que si (como por desgracia ha pasado) la política se convertía en la primera y fundamental actividad, a que se subordinaban todas las otras, la consecuencia era el recorte o envilecimiento del individuo. Es en ese sentido que combatió lo que he llamado la idolatría de la historia. En un texto de 1948, El destierro de Helena, dedicado a deplorar que Europa haya renegado de Grecia, escribió: 'Colocando la historia sobre el trono de Dios, marchamos hacia la teocracia, igual que aquellos a quienes los griegos llamaban bárbaros y a quienes combatieron en la batalla de Salamina' ${ }^{14}$. De Camus adopta además su desconfianza a las abstracciones, su apuesta por la vida y su rechazo a las ideas generales convertidas en dogmática o en sistemas ideológicos a los cuales los ideólogos — partiendo por los custodios del socialismo - se empeñan en reducir la sociedad.

También tiene que haber sido importante en su evolución intelectual el fracaso del militarismo populista que ensayó el general Velasco Alvarado en el Perú y respecto del cual, a diferencia de buena parte de la izquierda peruana, siempre mantuvo - aparte de un marcado desdén- las manos limpias, entre otras cosas porque su condena a las dictaduras - de izquierda, de centro o de derecha, cupulares o populistas, de signo privatizador o estatista - es total y no admite excepciones.

Es así que finalmente desembarca en las costas del pensamiento liberal. El proceso contempló incluso un encuentro privado con Margareth Thatcher en Downing Street, unido a posteriores testimonios de genuina admiración. El gran punto de inflexión, sin embargo, fue el ensayo "Isaiah Berlin, un héroe de nuestro tiempo", de noviembre de 1980, fechado en Washington. Fue en muchos sentidos un aconte-

${ }^{14}$ Mario Vargas Llosa, “Albert Camus y la moral de los límites”, 1985, p. 231. 
cimiento, un campanazo, una prueba irrefutable de conversión interior. Bien podría ser uno de los más sentidos, hermosos y convincentes artículos que columnista alguno haya escrito sobre un pensador que - aparte de inteligencia, sensatez y erudición - no tenía mucho más que ofrecerle al mundo: no tenía un programa mesiánico, no tenía tampoco una gran convocatoria que hacer $\mathrm{y}$, menos todavía, una fórmula que ofrecer para generar al hombre nuevo. Escribe Vargas Llosa: "La más sorprende característica de este pensador es —a simple vista- la de carecer de un pensamiento propio. Parece un sinsentido decir algo semejante, pero no lo es, pues, cuando uno lo lee, tiene la impresión de que Isaiah Berlin consigue en sus ensayos eso que, después de Flaubert (y gracias a él), han tratado de conseguir la mayoría de los novelistas modernos en sus novelas: abolirse, invisibilizarse, dar la ilusión de que sus historias son autogeneradas. Hay muchas técnicas para 'desaparecer al narrador' en una novela. La técnica que emplea el profesor Berlin para hacernos sentir que él no está detrás de sus textos es el fair play. Es decir, la escrupulosa limpieza moral con que analiza, expone, resume y cita el pensamiento de los demás, atendiendo todas sus razones, considerando los atenuantes, las limitaciones de época, no empujando jamás las palabras o las ideas ajenas en una dirección u otra para de este modo acercarlas a las propias. Esta impresión de objetividad en la transmisión de lo inventado por los demás hace que tengamos la fantástica impresión de que, en estos libros que dicen tantas cosas, Isaiah Berlin mismo no tenga nada que decir"15.

Como esa impresión —claro- es absoluta y completamente falsa, el autor dedica el resto del ensayo a analizar la originalidad y consistencia de sus planteamientos y contribuciones.

En realidad no se trata solo de reivindicar a uno a los iconos de la filosofía analítica británica del siglo XX. El artículo de Vargas Llosa combina el análisis de los escritos de Berlin con la experiencia personal suya y con las convicciones que se ha ido forjando como intelectual latinoamericano a lo largo de la vida, a golpe de entusiasmos, decepciones, evidencias, insatisfacciones, revelaciones y aprendizajes.

Hacia el final de ese artículo memorable, Vargas Llosa dice que de todos los libros que ha leído en los últimos años, el de Berlin es uno de los que más lo ha impresionado: "Sus opiniones filosóficas, históri-

15 Mario Vargas Llosa, "Isaiah Berlin, un héroe de nuestro tiempo", 1985 , p. 407. 
cas y política — escribe- me parecen esclarecedoras, compartibles"16. Pero hay un gran pero y quien lo plantea no es el Vargas Llosa-ensayista sino el Vargas Llosa-novelista. Porque al lado de la comprensión profunda que muestra el profesor Berlin de la vida de las personas, de la forma en que se comportan las sociedades, de los cursos de la historia humana y del influjo de las ideas en la experiencia cotidiana, existe otra dimensión del hombre que es irreductible desde el punto de vista intelectual porque se trata de una dimensión que no cabe en las clasificaciones, que rehúsa las categorizaciones, que se sale de los modelos y que se resiste a las disciplinas de la razón. Es el mundo del instinto y el de la sinrazón, el de los demonios y el del inconsciente, el de los sueños y las patologías, el de las obsesiones que esclavizan y de los traumas que destruyen. Para entender aquel complejo mundo de allá se necesitan mentes como las de Isaiah Berlin. Para entender esta caótica zona de acá — parece no haber otra salida - tienen que venir los artistas. Son ellos quienes mejor pueden explicarse esta faceta. Tienen que hacerlo, entre otras cosas porque la vida humana combina las dos en proporciones que son difíciles de anticipar.

Esa percepción, en orden a que el intelectual trabaja con las ideas y el novelista con los demonios, al final sigue estando presente en Vargas Llosa. Fue precisamente esto lo que tanto irritó en su época a Ángel Rama. Al ilustre crítico uruguayo le pareció embarazoso semejante tributo a la teología. A juicio suyo era un guiño completamente reñido con el proceso histórico que América Latina estaba viviendo en dirección a una revolución que era inminente. Todo lo que oliera a religión le resultaba incongruente proviniendo de un escritor que se había declarado químicamente ateo. Tal vez por eso, porque el novelista negocia su arte en el submundo errático de los demonios y no bajo la luz diáfana de la sensatez y de la razón, todas las novelas de Vargas Llosa están pobladas por personajes desorbitados, excesivos, sobregirados, demenciales, disfuncionales y obstinados. Son personajes que están gobernados por impulsos que los sacan de sí y los llevan a un encuentro más o menos destructivo y épico con su propio destino. Parecería que hay una fatalidad muy anterior a ellos pero que de todos modos los domina, los justifica, los moviliza, los devora y los olvida. Eso puede ser un escándalo, pero no habría mucho espacio para recriminarnos porque así discurre la historia y así también funciona la vida.

${ }^{16}$ Ibídem, p. 423. 
A los que aman la coherencia por sobre todo y se molestan mucho con las disociaciones les gustaría creer que en la producción novelística, ensayística y periodística de Vargas Llosa hay un continuo movilizado por las mismas lógicas, animado por los mismos ideales, alumbrado por la misma energía y cruzado por las mismas convicciones. Obviamente no es así. El de las novelas es el Vargas Llosa más arriesgado, con muchas dudas, que se enfrenta a mundos y experiencias que son ajenos a sus convicciones y para los cuales no tiene mucha respuesta. El de los ensayos - ensayos básicamente de temas literarios- es el de una inteligencia portentosa que escudriña, lee, analiza, compara, visualiza escenarios y formula hipótesis. El Vargas Llosa de la producción periodística, finalmente, es un observador que sabe mirar con especial inteligencia y atención la actualidad y que aplica a lo que ve el fuego de sus convicciones. El de las novelas es un hombre lleno de dudas; el de los ensayos, una mente curiosa comprometida en sucesivas búsquedas; el de las columnas, un observador, un investigador, un provocador o un converso que, aparte de combinar historias ajenas con experiencias propias, opina, contextualiza, enjuicia, exalta o condena

Fujimori padre y Fujimori hija, el general Pinochet, el México del PRI, la Venezuela de Chávez y la Argentina peronista — entre otros blancos - saben perfectamente, o lo supieron en otra época, lo que es tener a Vargas Llosa de enemigo. Hay pocas plumas más virulentas e incisivas que la suya. El mejor Vargas Llosa suele florecer en la polémica. Se diría que en ese momento despierta el fanático que alguna vez fue y que, en alguna zona al menos, quizás sigue siendo. En el prólogo de uno de sus mejores libros de recopilación de artículos, El lenguaje de la pasión, título que envuelve un homenaje a Octavio Paz, Vargas Llosa confiesa que "siempre trato de escribir de la manera más desapasionada posible, pues sé que la cabeza caliente, las ideas claras y una buena prosa son incompatibles" ${ }^{\prime 17}$. Bueno, las recientes columnas dedicadas a la elección presidencial peruana —explicando por qué votará por Humala y no por Keiko o diciéndole al cardenal Juan Luis Cipriani, arzobispo de Lima, que no es él el interlocutor más indicado para cuestionar su apoyo a Ollanta en segunda vuelta— devuelven en gloria y majestad al

${ }^{17}$ Mario Vargas Llosa, El lenguaje de la pasión, 2000, p. 7. 
intelectual que no se vende por los regaloneos y aplausos de la elite ni que tampoco se deja amedrentar por la indignación de los poderosos. De alguna manera, el Premio Nobel, había vuelto a reconciliarse con el Perú. La gente que lo lee en su patria volvía a aplaudirlo. Para Vargas Llosa tanto o más traumático que su derrota en la elección presidencial del año 90 fue comprobar, con dolor y alguna dosis de resentimiento, que medio país, incluyendo a muchos de sus propios aliados y a connotados dirigentes de su campaña, se entregaba atado de pies y manos a un político oportunista, corrupto y de muy frágiles convicciones democráticas. Ese vasallaje es el que Vargas Llosa todavía no perdona y le pone a hervir la sangre cada vez que se acuerda. $Y$ es ese fantasma el que ha vuelto a interferir con una cuña insalvable su relación con el Perú blanco, pijo y dirigente.

Alarmado por la deserción de las elites, desilusionado por el repliegue de la academia a lenguajes oscuros e impenetrables, desanimado por la decadencia de la crítica, golpeado por el desprestigio de la política, la degradación de los medios y todos los fenómenos asociados a lo que él llama "la civilización del espectáculo", Vargas Llosa tiene hoy un diagnóstico casi apocalíptico, en todo caso muy sombrío, de la banalización de la cultura en los tiempos que corren. Curiosamente, sin embargo, sus crónicas y columnas, en la medida en que suben la vara y mantienen la bandera en alto, hacen pensar que no todo está perdido, al menos mientras la prensa siga abriéndose a mentes y plumas como la suya.

\section{OBRAS CITADAS}

Vargas Llosa, Mario. Contra viento y marea (1962-1982) [1983]. Sudamericana-Planeta, 1985.

"Carta a Haydée Santa María". En Mario Vargas Llosa, Contra viento y marea (1962-1982) [1983]. Sudamericana-Planeta, 1985.

_ "Carta de Fidel Castro". En Mario Vargas Llosa, Contra viento y marea (1962-1982) [1983]. Sudamericana-Planeta, 1985.

"Entrevista exclusiva a V. Ll.". En Mario Vargas Llosa, Contra viento y marea (1962-1982) [1983]. Sudamericana-Planeta, 1985.

García Márquez, Historia de un deicidio. Seix Barral, 1971.

“Albert Camus y la moral de los límites". En Mario Vargas Llosa, Contra viento y marea (1962-1982) [1983]. Sudamericana-Planeta, 1985. 
"Isaiah Berlin, un héroe de nuestro tiempo". En Mario Vargas Llosa, Contra viento y marea (1962-1982) [1983]. Sudamericana-Planeta, 1985.

- El pez en el agua. Seix Barral, 1993.

El lenguaje de la pasión. Ediciones El País, 2000.

"La casa de Arequipa". La Tercera, 27 de marzo 2011. 